\title{
The frequency in Japanese of genetic variants of 22 proteins
}

\author{
IV. Acid phosphatase, NADP-isocitrate dehydrogenase, peptidase A, \\ peptidase $B$ and phosphohexose isomerase
}

\author{
By R. J. TANIS, * N. UEDA, $\dagger$ C. SATOH, $\dagger$ R. E. FERRELL, * $\ddagger$ S. KISHI- \\ MOTO, $\dagger$ J. V. NEEL, $*$ H. B. HAMILTON, $\dagger$ AND N. OHNO $\dagger$
}

\section{INTRODUCTION}

This paper presents the results of surveying for electrophoretic variants the following five erythrocyte enzymes: acid phosphatase (ACP, EC 3.1.3.2), NADP-isocitrate dehydrogenase $\left(\mathrm{ICD}_{\mathrm{g}}\right.$, EC 1.1.1.14), peptidase A (PEPA), peptidase B (PEPB) and phosphohexose isomerase (PHI, EC 5.3.1.9), utilizing blood samples collected from Japanese adults residing in Hiroshima and Nagasaki. Special emphasis is placed on the rare genetic variants we have observed, but data are given on the A-B polymorphism of ACP. For a more complete characterization of the nature of the population sampled and the circumstances under which the collections were made the reader is referred to the first paper in this series (Ferrell et al. 1977). As before, the convention in designating variants which do not clearly correspond to previously reported types will be by city and order of discovery, abbreviating Hiroshima as HIR and Nagasaki as NGS.

\section{MATERIALS AND METHODS}

All systems were studied by vertical starch-gel electrophoresis, employing electrostarch (Electrostarch Co., Madison, Wisconsin). PHI types were determined using the electrophoretic and staining methods of Detter et al. (1968). A second slice of the PHI gel was used for the ICD $_{\mathrm{S}}$ studies, the enzyme being stained as described by Shaw \& Prasad (1970). The classifications of peptidase A and peptidase B were based on the method of Lewis \& Harris (1967), using the substrates L-valyl-L-leucine and L-leucylglycylglycine respectively; this choice of substrates was based upon the high degree of substrate specificity of the peptidase system. The acid phosphatase electrophoretic conditions are those described by Fildes \& Harris (1966); the ACP bands were visualized using the phenolphthalein diphosphate method (Hopkinson, Spencer \& Harris, 1964). The procedures of sample preparation and storage are described in an earlier paper in this series (Ueda et al. 1975). During the course of this work a number of isoenzyme patterns, for a variety of reasons, did not yield patterns which could be typed with sufficient confidence. For this reason we have omitted these, designated 'no types', from the final totals.

* Department of Human Genetics, University of Michigan, Ann Arbor, Michigan 48109. Financial support for the study derived from Contract E(11-1)-1552 with the Energy Research and Development Administration, Washington, D.C.

$\dagger$ Radiation Effects Research Foundation, Hiroshima, Japan. The Foundation, the successor to the Atomic Bomb Casualty Commission (ABCC), was established in April 1975 as a private non-profit Japanese Foundation, under the auspices of the Ministry of Health and Welfare and Finance Ministry, supported equally by funds from the Government of Japan through the Ministry of Health and Welfare, and the Government of the United States through the National Academy of Sciences under contracts with the Energy Research and Development Administration, the National Cancer Institute and the National Heart and Lung Institute.

$\ddagger$ Present address: Center for Demographic and Population Genetics, Graduate School of Biomedica Sciences at Houston, The University of Texas, Houston, Texas 77025. 
Table 1. Phenotype and gene frequencies for the erythrocyte acid phosphatase polymorphism in Hiroshima and Nagasaki

\begin{tabular}{|c|c|c|c|c|c|c|c|c|}
\hline \multirow[b]{2}{*}{ City } & \multicolumn{4}{|c|}{ Phenotype } & \multicolumn{2}{|c|}{ Gene frequency } & \multirow[b]{2}{*}{$x^{2}$} & \multirow[b]{2}{*}{$P$} \\
\hline & $A$ & $\mathrm{AB}$ & $\mathbf{B}$ & Total & $\mathbf{P}^{\mathbf{A}}$ & $\mathbf{P}^{\mathbf{B}}$ & & \\
\hline Hiroshima & $8 I$ & 701 & 1513 & 2295 & 0.188 & 0.812 & 0.0003 & $0.98<P<0.99$ \\
\hline Nagasaki & 32 & 173 & 290 & 495 & 0.239 & 0.761 & 0.8064 & $0.30<P<0.50$ \\
\hline Total & 113 & 874 & 1803 & 2790 & 0.197 & 0.803 & & \\
\hline
\end{tabular}
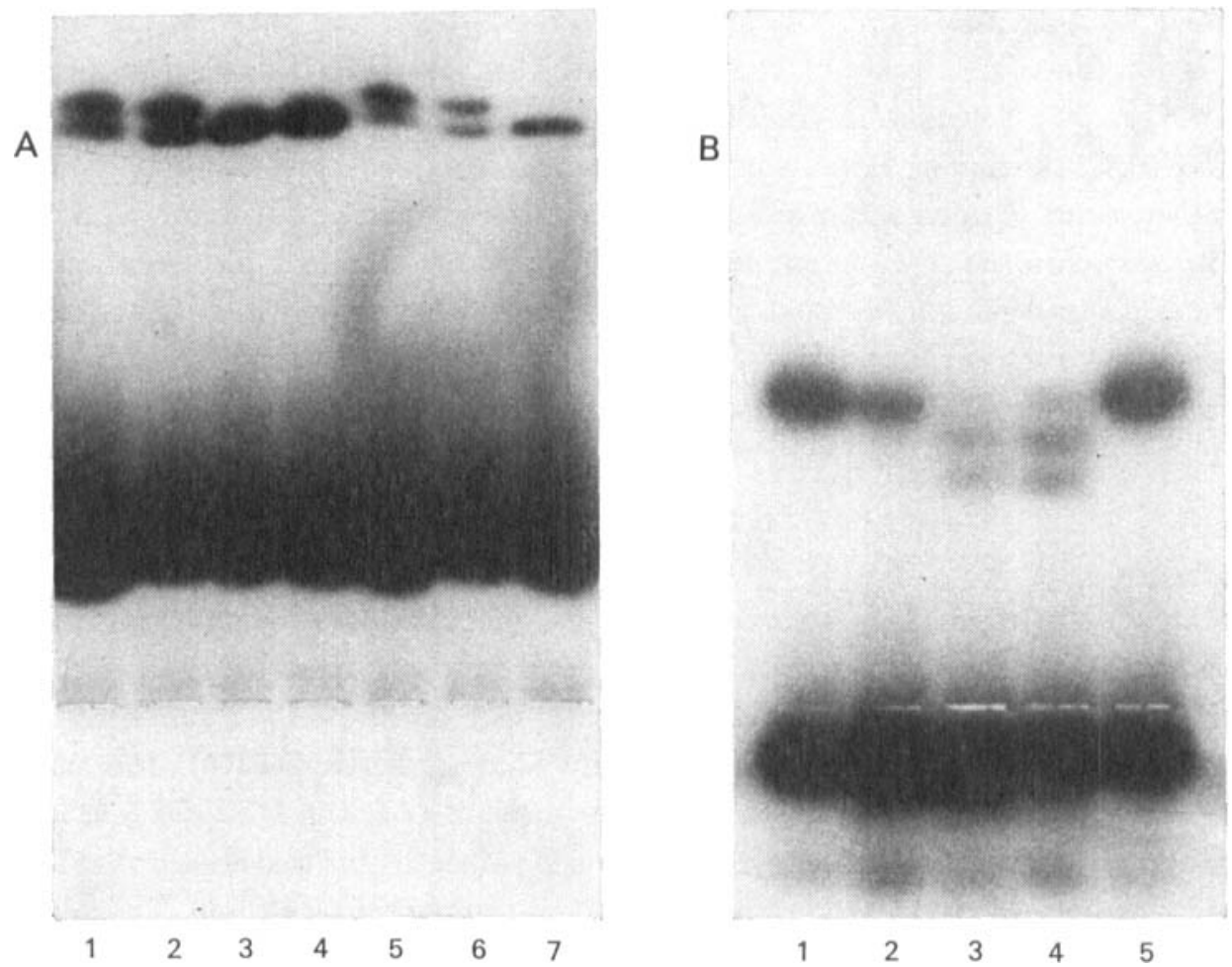

Fig. 1. (A) Starch-gel electrophoresis patterns of $\operatorname{ICD}_{8} 1-2_{H_{1 R}}$ : Wells 1, 2, 5 and 6 contain the $\operatorname{ICD}_{s}$ 1-2 HIR $1_{1}$ variant; wells 3,4 and 7 contain normal controls. (B) Starch-gel electrophoresis patterns of the peptidase $A$ typo 1-4 $\mathbf{H I R}_{1}$ variant: wells 1 and 5 represent the normal peptidase $A$ pattern; well 2 , a daughter of the propositus showing a normal pattern; well 3, a daughter of the propositus showing the variant pattern; well 4 , propositus (330394).

\section{RESULTS \\ Acid phosphatase \\ Population screening for the acid phosphatase polymorphism in Japan has been carried out on a large scale and the work has recently been reviewed (Ishimoto, 1975). The results of our screening of 2790 individuals are shown in Table 1. In both cities there is agreement with Hardy- Weinberg proportions. The observed frequencies of the $A C P_{1}^{\Lambda}$ and $A C P_{1}^{\mathrm{B}}$ alleles fall well within the range reported for other Japanese populations, and our findings are very similar to those previously reported for Hiroshima Prefecture (Ishimoto, Kuwata \& Kubota, 1973) and for}


Table 2. Summary of the family studies for the rare electrophoretic variants of $I C D_{S}, P E P A, P E P B$, and PHI

\begin{tabular}{|c|c|c|c|c|c|c|c|c|}
\hline \multirow[b]{2}{*}{ System } & \multirow[b]{2}{*}{ Variant } & \multirow[b]{2}{*}{ City } & \multirow[b]{2}{*}{ Propositus } & \multirow[b]{2}{*}{ Sex } & \multicolumn{4}{|c|}{ Family studies } \\
\hline & & & & & Mo & $\mathrm{Fa}$ & Sibs & Children \\
\hline $\begin{array}{l}\text { Isocitrate } \\
\text { dehydrogenase }\end{array}$ & $2_{\mathrm{HIR} 1}$ & $\mathrm{H}$ & 210273 & $\mathbf{M}$ & 一 & - & - & $* q$ \\
\hline Peptidase A & 4HIR 1 & $\begin{array}{l}\mathbf{H} \\
\mathbf{N} \\
\mathbf{N} \\
\mathbf{H}\end{array}$ & $\begin{array}{l}330394 \\
025746 \\
068853 \\
844958\end{array}$ & $\begin{array}{l}F \\
F \\
F \\
F\end{array}$ & $\begin{array}{l}- \\
- \\
-\end{array}$ & $\frac{-}{\overline{0}}$ & $\frac{\overline{-}}{* \bar{q}}$ & 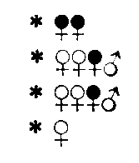 \\
\hline Peptidase B & 3HIR 1 & $\begin{array}{l}\mathbf{N} \\
\mathrm{H} \\
\mathrm{H} \\
\mathrm{N} \\
\mathbf{N}\end{array}$ & $\begin{array}{l}004594 \\
302142 \\
242008 \\
111531 \\
131322\end{array}$ & $\begin{array}{c}M \\
M \\
F \\
F \\
M\end{array}$ & $\begin{array}{l}\bar{Z} \\
\bar{Z} \\
?\end{array}$ & $\begin{array}{l}\bar{Z} \\
\overline{-} \\
0\end{array}$ & $\begin{array}{l}- \\
\overline{-} \\
-\end{array}$ & 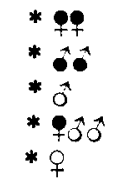 \\
\hline \multirow[t]{22}{*}{$\begin{array}{l}\text { Phosphohexose } \\
\text { isomerase }\end{array}$} & $2_{\mathrm{XGS} 1}$ & $\mathbf{N}$ & 086757 & M & 一 & 一 & 一 & $* q \hat{O}$ \\
\hline & \multirow[t]{18}{*}{$\begin{array}{l}3 \mathrm{NGS} 1 \\
4 \mathrm{HIR} 1\end{array}$} & $\begin{array}{l}\mathrm{H} \\
\mathrm{N}\end{array}$ & $\begin{array}{l}293863 \\
063964\end{array}$ & $\begin{array}{l}\mathbf{M} \\
\mathbf{M}\end{array}$ & $\frac{9}{-}$ & - & $*$ & $* \bar{q}$ \\
\hline & & $\mathrm{N}$ & 090378 & F & - & - & q & $* 7$ \\
\hline & & $\mathbf{H}$ & 200448 & F & - & - & 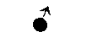 & *q \\
\hline & & $\mathbf{H}$ & 207013 & M & - & - & - & $\hat{0}$ \\
\hline & & $\mathbf{H}$ & 222973 & $\mathrm{~F}$ & - & 一 & 一 & * \%? \\
\hline & & $\mathbf{H}$ & 220925 & $\mathbf{M}$ & - & - & - & $* 00$ \\
\hline & & $\mathrm{N}$ & $000790 \dagger$ & $\mathrm{F}$ & - & - & $* q 0^{*}$ & - \\
\hline & & $\mathbf{H}$ & 234948 & $\mathrm{~F}$ & - & 一 & $\overrightarrow{0}$ & * 0 \\
\hline & & $\begin{array}{l}\mathbf{N} \\
\mathrm{H}\end{array}$ & 001743 & $\begin{array}{l}\mathrm{F} \\
\mathrm{F}\end{array}$ & - & - & - & $* \dot{0}$ \\
\hline & & $\mathbf{H}$ & $\begin{array}{l}331428 \\
361321\end{array}$ & $\mathbf{F}$ & - & - & - & * $\underset{+}{q}$ \\
\hline & & $\mathbf{N}$ & 016809 & M & - & 一 & - & * At? \\
\hline & & $\mathbf{N}$ & 016882 & $\mathbf{F}$ & - & 一 & 一 & * \\
\hline & & $\mathbf{N}$ & 081854 & $\mathbf{F}$ & 一 & 一 & - & * 49 \\
\hline & & $\mathbf{N}$ & 012613 & $\mathbf{F}$ & - & 一 & $* \sigma^{*}$ & SOÁ7 \\
\hline & & $\mathbf{N}$ & $15003 \mathrm{I}$ & $\mathbf{M}$ & - & 一 & *\%o & otơ \\
\hline & & $\mathbf{N}$ & 031096 & $\mathbf{F}$ & - & - & 一 & * 6 \\
\hline & & $\mathrm{N}$ & 163250 & $\mathbf{M}$ & - & - & - & $* q$ \\
\hline & & $\mathbf{N}$ & $02795^{8}$ & $\mathbf{F}$ & - & - & $* q$ & 一 \\
\hline & \multirow[t]{3}{*}{5 HIR 1} & $\mathbf{H}$ & 363703 & M & - & - & - & $* q$ \\
\hline & & $\mathbf{N}$ & 030539 & $\mathbf{F}$ & 一 & 一 & - & * 0 \\
\hline & & $\mathrm{H}$ & 212313 & $\mathrm{~F}$ & - & 一 & - & * $\wp$ \\
\hline
\end{tabular}

* Indicates first primary relative tested in the family study.

$\dagger 000790$ is the elder sister of 027958 . $\quad \ddagger 02795^{8}$ is the younger sister of 000790 .

Nagasaki Prefecture (Ishimoto \& Kuwata, 1973a). There is no significant difference between the frequency of the $A C P_{1}^{\mathrm{A}}$ allele in Hiroshima and Nagasaki. Although a few isolated cases of acid phosphatase patterns resembling the C-A and C-B types have been reported (Ishimoto, 1975), the apparent absence of the $\mathrm{C}$ type in this study is in agreement with the reports of others showing the extreme rarity of this type of Japanese populations. 

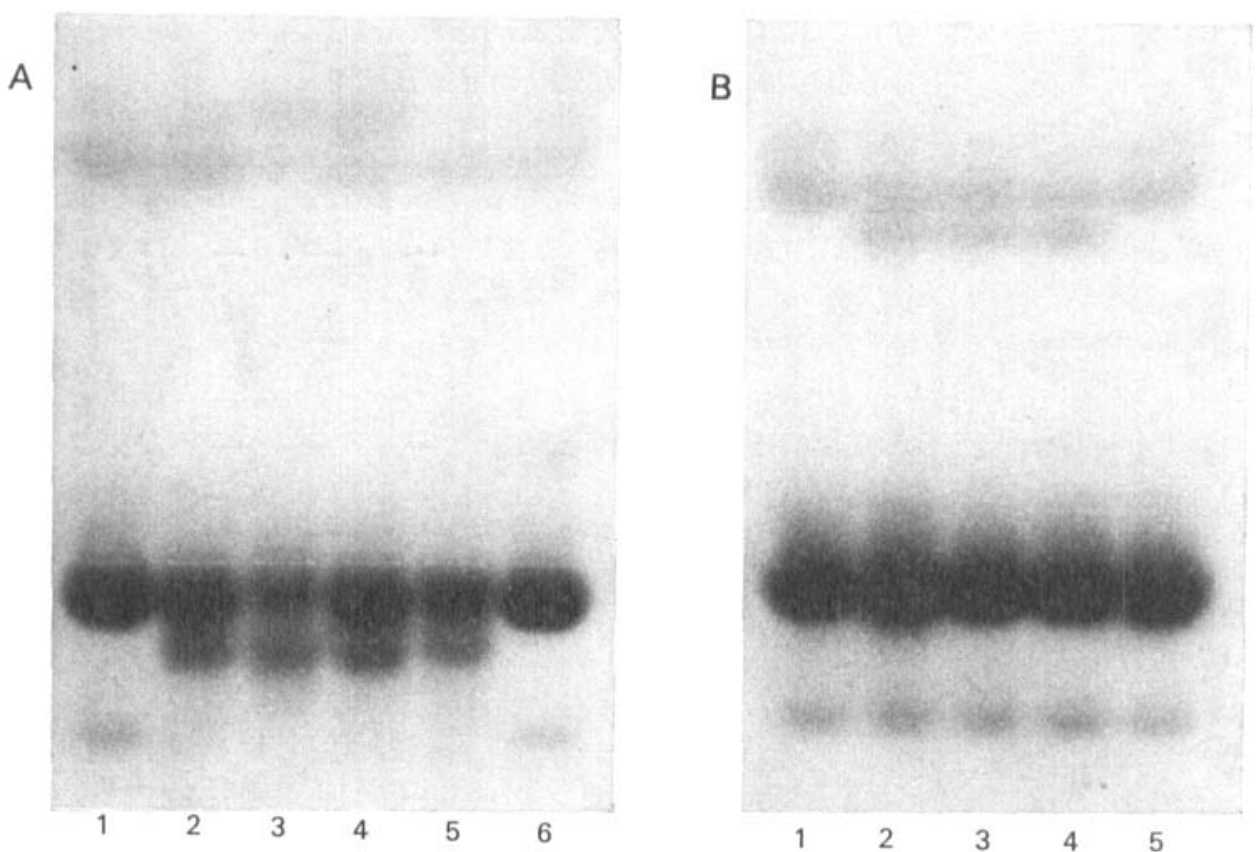

Fig. 2. Starch-gel electrophoresis patterns obtained during family studies of the peptidaso B variants. (A) Peptidase B type 1-3 $\mathbf{H I R ~} 1_{1}$ : wells 1 and 6, normal controls; wells 2 and 5, two sons showing the normal PEPB pattern; well 3, propositus (111531) showing the variant pattern; well 4, daughter of the propositus. (B) Peptidase B type 1-2 Nas $1_{1}$ : wells 1 and 5 , normal controls; well 2, propositus (302142); wells 3 and 4, two sons of propositus showing the variant pattern.

\section{Isocitrate dehydrogenase,}

We have encountered a single variant of isocitrate dehydrogenase, in a Hiroshima resident, in a sample of 3993 individuals typed. An additional 36 individuals could not be typed because of low or absent $\mathrm{ICD}_{\mathrm{S}}$ activity in the standard preparation. The one $\mathrm{ICD}_{\mathrm{S}}$ variant has been designated 1-2 $\mathrm{HIR}_{1}$; the electrophoretic pattern of this sample is shown in Fig. $1 \mathrm{~A}$. This pattern appears to be the same as that of the type 1-2 reported by Chen, Fossum \& Giblett (1972) in one of 184 Japanese-Americans residing in Seattle, Washington. The genetic basis of the variant encountered in this study has been established by the family study shown in Table 2 . The type 1-2 ICD phenotype has been reported in Japan by Ishimoto \& Kuwata (1973a), who observed two examples in 606 blood donors from Nagasaki Prefecture. Shinoda, Matsunaga \& Koshinaga (1974) have reported an unspecified electrophoretic variant of $\mathrm{IDC}_{\mathrm{S}}$ in a study of tissue enzymes from 98 individuals, and from the information given by Ishimoto (1975) it is assumed that this variant also exhibits the 1-2 pattern. Thus far the type $2 \mathrm{ICD}_{\mathrm{S}}$ variant has not been encountered in non-Mongoloid populations.

\section{Peptidase A}

A total of six electrophoretically identical variants of PEPA, designated $1-4_{11 I_{1}}$, were seen in our sample of 4009 individuals; three among 2638 specimens from Hiroshima and three among 1371 from Nagasaki. No genetic relationship between the six persons could be established. An additional 20 individuals gave an electrophoretic pattern for PEPA which was too weak to type accurately. In addition to those patterns too weak to be typed, a number of specimens exhibited 
normal electrophoretic patterns but with a substantially reduced staining intensity. It is possible that this was due to the presence of the quantitative variant of PEPA described by Lewis (1973), but the studies necessary to establish this point were not carried out. Omoto \& Harada (1972) havealso reported the presence of quantitative variation in PEPA, in a sample of 125 Ainu.

The electrophoretic pattern of the PEPA variant resembles that of a phenotype designated as $1-4$ by Lewis \& Harris (1967). The pattern is shown in Fig. $1 \mathrm{~B}$, wells 3 and 4 ; the observed pattern is consistent with the dimeric properties of this enzyme. Limited family studies were possible for four of the six cases, and the variant phenotype was observed in additional family members in three of these cases. The family studies are summarized in Table 2, and the starchgel results of one family study are presented in Fig. $1 \mathrm{~B}$.

The peptidase A type 1-4 appears to be quite rare in all populations tested to date. This or a very similar phenotype was first reported in a sample of 2283 Europeans by Lewis \& Harris (1967). Ishimoto \& Kuwata (1973b) have reported one example of the 1-4 phenotype in 1070 Japanese blood donors from Mie Prefecture.

\section{Peptidase $B$}

We have examined 4028 individuals for red cell PEPB variation (2652 from Hiroshima and 1376 from Nagasaki). In addition, one Hiroshima specimen could not be typed. Two examples, one from Hiroshima and one from Nagasaki, were observed of a variant designated PEPB $1-2_{N G S 1}$, and six individuals, three from each city, were encountered with a pattern designated

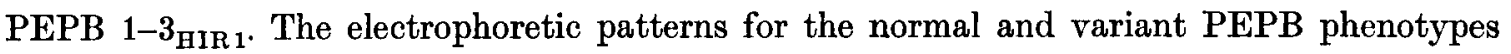
are shown in Fig. 2. The electrophoretic patterns of the two individuals with the $2_{\mathrm{NaS}} \mathrm{v}$ variant closely resemble the 1-2 phenotype reported by Lewis \& Harris (1967) while our $1-3_{\mathrm{HIR} 1}$ phenotype appears comparable to the 1-3 phenotype demonstrated by the same authors, who encountered these phenotypes in a sample of 2197 Europeans. Ishimoto \& Kuwata (1973b) have reported two examples of the PEPB 1-2 phenotype in a sample of 1070 blood donors from Mie Prefecture in central Japan. To our knowledge the PEPB 1-3 phenotype, or anything closely resembling it, has not been previously reported in Japan. We have conducted limited family studies for these two variants and the genetic nature of the $2_{\text {NGS1 }}$ variant has been verified in both cases. In two of three cases of the type $1-3_{\mathrm{HIR} 1}$ the variant was detected in another family member. In the third case, only a single child was available for study; he exhibited a normal pattern. These results are summarized in Table 2, and the starch-gel patterns of a family study for each electrophoretic type are included in Fig. 2.

\section{Phosphohexose isomerase}

During the course of typing 4027 individuals for red cell PHI, we have encountered 35 variants, comprising 5 distinct electrophoretic types. The patterns of two additional persons could not be typed. The most commonly encountered variant, designated PHI 1-4 ${ }_{\text {HIR } 1}$, is electrophoretically similar to the type 1-4 first reported by Detter et al. (1968) in two of 441 samples from Thailand. We have seen 26 examples of the 1-4 ${ }_{\mathrm{HIR} 1}$ phenotype in our survey, 11 from Hiroshima and 15 from Nagasaki. The genetic transmission of the $\mathbf{4}_{\mathrm{HIR} 1}$ variant was confirmed in 12 of 19 limited family studies; these 19 family studies are summarized in Table 2. An electrophoretic comparison of this and the other PHI variants encountered in this study is shown in Fig. 3, and summarized in Table 3. We have also detected, in a single individual from Hiro- 

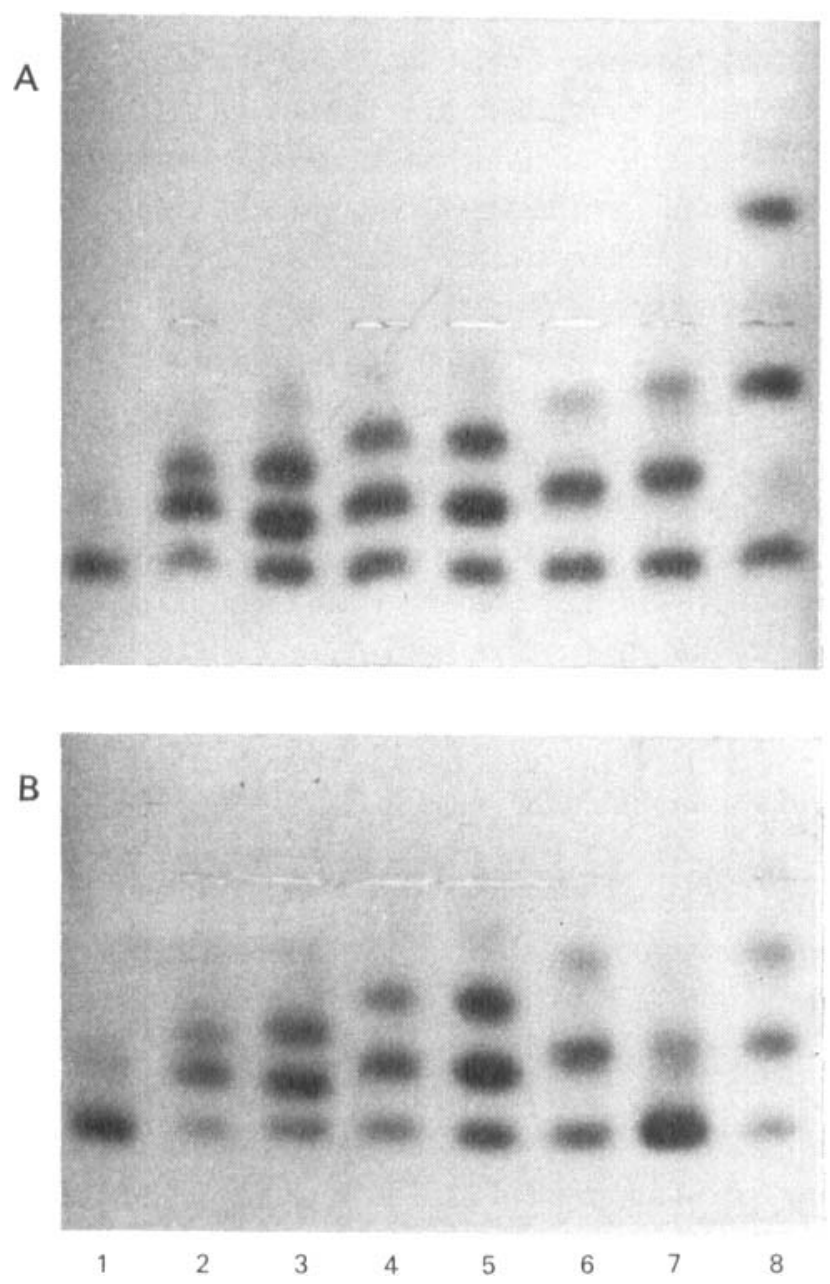

Fig. 3. Starch-gel electrophoresis of the phosphohexose isomerase variants showing the effect of 2-mercaptoethanol. (A) Without the addition of 2-mercaptoethanol to the samples. (B) After the addition of 2-mercaptoethanol: well 1 normal PHI type 1 control; well 2, 1-2-like variant obtained

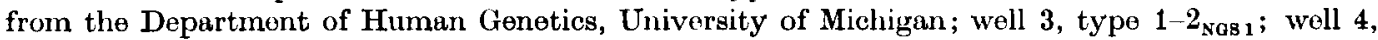
type 1-3 standard (confer toxt); well 5 , type 1-3 $3_{\text {IIR } 1}$; well 6 , typo $1-4_{\mathrm{HIR} 1}$; well 7 , type $1-5_{\mathrm{Nes} 1}$; well 8 , type $1-5_{\text {RIR } 1}$.

shima, a phenotypic pattern which we have designated $1-\mathbf{3}_{\text {IIIR } 1}$. The mobility and intensity pattern of this variant are indistinguishable from a standard PHI type 1-3 provided by Dr Eloise Giblett. A limited family study confirmed the genetic nature of this variant (confer Table 2).

Furthermore, we have seen three examples, all from Nagasaki, of a variant, designated 1-2 NGS $1_{1}$, which has an electrophoretic pattern similar to the type 1-2 first reported by Detter et al. (1968) in a single sample of the 441 Thai bloods which they examined. This pattern is shown in Fig. 3 and the result of the single family study that was possible is included in Table 2. In addition, we have encountered three examples (two in Hiroshima and one in Nagasaki) of a variant which, when the haemolysate is very fresh, has an electrophoretic pattern resembling the type 1-5 phenotype shown by Detter et al. (1968). However, our variant has properties which may distinguish it from the previously reported PHI 1-5 type, and we shall term this variant 


\section{Table 3. Summary of phosphohexose isomerase variants in Hiroshima and Nagasaki}

$\begin{array}{crrr}\text { Type } & \text { Hiroshima } & \text { Nagasaki } & \text { Combined } \\ \text { I } & 2637 & \text { I 355 } & 3992 \\ \text { I-2 } \text { Nas 1 } & 0 & 3 & 3 \\ \text { I-3HIR 1 } & \text { I } & 0 & \text { I } \\ \text { I-4HIR 1 } & \text { I I } & \text { I5 } & 26 \\ \text { I-5 Nas 1 } & 0 & 2 & 2 \\ \text { I-5HIR 1 } & 2 & \text { I } & 3 \\ \text { No types } & 2 & 0 & 2 \\ \text { Total } & 2653 & \text { I } 376 & 4029\end{array}$

* These samples gave patterns which stained too weakly to be typed accurately.

$1-5_{\text {HIR } 1}$. The genetic nature of the variant has been confirmed in a family study (Table 2). In their original report of the PHI phenotypes, Detter et al. (1968) noted that the 1-5 pattern seen in a fresh haemolysate was difficult to distinguish from that usually seen in the most frequent PHI 1 phenotype; the typical PHI 1-5 pattern appeared after 1-2 weeks of storage at an unspecified temperature. They were able to reverse this storage-dependent change in electrophoretic pattern by the addition of 2-mercaptoethanol to the sample. Hopkinson (1970) has also reported detailed experiments which show that the PHI 1-5 pattern can be generated by the reaction of oxidized glutathione with a free sulphydryl group in the variant through the formation of a disulphide bond.

Our three samples, exhibiting the PHI 1-5-like phenotypic pattern when a fresh haemolysate is used, also demonstrate an ageing effect; after storage the pattern closely resembles the PHI 1-6 pattern reported by Detter et al. (1968). Storage of the sample for 1 to 2 weeks at $4^{\circ} \mathrm{C}$ is sufficient to produce the effect. This storage-generated 1-6 pattern can be restored to the original 1-5-like pattern by treatment of the sample with $0.02 \mathrm{M} 2$-mercaptoethanol, as shown in Fig. 3. Following the argument of Hopkinson (1970) this suggests that, in this variant, a positively charged amino acid has been replaced by a cysteine, and that the 1-6 pattern arises from the reaction of that cysteine with oxidized glutathione in a manner analogous to the PHI 1-5 reported by Detter and co-workers. The effect of this would be to give the variant molecule a negative charge increase relative to the normal molecule. This proposal is completely consistent with the starch-gel patterns shown in Fig. 3. Ishimoto \& Kuwata (1974) have recently reported a single example of a PHI variant which shows the same pattern and behaviour towards thiol reagents as $1-5_{\mathrm{HIR} 1}$, and we presume it to be the same variant. Regrettably it is not known what the effect of reducing agents might be on the original sample Detter and coworkers designated as a type 1-6.

Finally, two individuals, both from Nagasaki, showed a PHI gel pattern essentially identical to the 1-4 $4_{\text {HIR } 1}$ discussed earlier. However, further experimentation revealed this pattern occurred only in the absence of 2-mercaptoethanol; when 2-mercaptoethanol was added to the haemolysate there was a considerable difference in the subsequent electrophoretic behaviour of the two Nagasaki samples relative to the other $1-4_{\mathrm{HIR} 1}$ samples. These differences are clearly illustrated in Fig. 3 where it is shown that the pattern in these two samples reverts to a normal type 1 pattern in the presence of thiol while the $1-4 \mathrm{HIR}_{1}$ pattern remains unaltered. Based on the electrophoretic shift in the presence of the reducing agent we have designated this variant 
type as $1-5_{\text {NGS } 1}$. During such comparisons only fresh samples were employed in making this distinction between the $1-4_{\mathrm{HIR} 1}$ and $1-5_{\text {NGS } 1}$ patterns since we have observed that haemolysates which initially showed the PHI $1-5_{\text {NGS } 1}$ patterns failed to respond to reducing agent following long-term storage.

The occurrence of PHI variants has been reported in a number of studies of Japanese populations (Ishimoto, 1975), but their distribution seems variable. Ishimoto et al. (1973) have reported results from the screening of 526 hospital outpatients in Hiroshima. They observed six examples of a phenotype resembling the PHI 1-4 and two cases resembling the PHI 1-6. It would be of interest to determine the effect of reducing reagents on this reported 1-6 pattern; no pattern resembling the PHI 1-3 phenotype was encountered. Ishimoto \& Kuwata $(1973 a, c)$ have also reported the presence of the PHI 1-4 and the absence of the PHI 1-3 in Nagasaki and Kagoshima Prefectures.

The limited data available suggest some local differences in the frequency of occurrence of rare PHI phenotypes in Japan. A phenotype similar to the PHI 1-4 is seen in Kyushu and southern Honshu, but not the PHI 1-3 type (Ishimoto \& Kuwata, $1973 a, c$; Ishimoto et al. 1973). The PHI 1-3 and 1-4 phenotypes appear together in populations from central Honshu (Shinoda, 1970; Shinoda et al. 1974; Ishimoto \& Kuwata, 1974), and the PHI 1-3, but not the 1-4, phenotype is seen in northern Honshu (Harada et al. 1971).

The PHI 1-2 phenotype seems to be very rare in Japanese populations, having been seen in only two other studies (Ishimoto \& Kuwata, 1973a, 1974). Shinoda \& Matsunaga (1970) have also reported an unusual phenotype which they designated $6-1 \mathrm{~J}$, but its behaviour upon treatment with 2-mercaptoethanol seems to distinguish it from the 1-5 HIR 1 type described here. Other reports of the 1-5-like phenotype in Japan are available, but with the exception of the case reported by Ishimoto \& Kuwata (1974), the effect of treatment with 2-mercaptoethanol on pattern alteration has not been described.

\section{DISCUSSION}

We have presented data on the occurrence of 49 examples of rare electrophoretic variants of four erythrocyte enzymes in a survey of 4029 individuals from Hiroshima and Nagasaki, Japan. Perhaps the most interesting aspect of this report is the occurrence of 35 variants of 5 distinct types in the PHI system. One of these types, an unusual PHI 1-5-like variant, presumably was previously seen in a single individual by Ishimoto \& Kuwata (1974). It has properties which seem to distinguish it from the PHI 1-6 originally encountered in a single Negro individual by Detter et al. (1968). In fresh samples this variant, designated $5_{\mathrm{HIR} 1}$, has an electrophoretic pattern similar to the previously reported PHI 1-5, and the 1-6-like pattern appears only after storage. A recent review (Ishimoto, 1975) has summarized the rather widespread occurrence of PHI 1-5like phenotypes in Japanese populations; in some of these populations the PHI 1-6 phenotype was also observed. In order to gain a clear understanding of the distribution of the unusual 1-5 type variants, it is of great importance to determine the response to storage in the presence and absence of reducing agent prior to electrophoresis.

The distribution of PHI variants in Asia and Oceania has been discussed by Omoto \& Blake (1972) and in Micronesia by Blake et al (1972) and Neel, Ferrell \& Conard (1976). The reported results suggest that the PHI 1-4 phenotype may be widespread among Mongoloid populations, but is absent in neighbouring Asian and in Micronesian populations. Our findings of 
26 cases of a PHI 1-4-like phenotype in 4029 individuals substantiates the widespread occurrence of this phenotype in the Japanese. This work and the reports of others suggests an uneven distribution of the PHI 1-4 and 1-3 types within the Japanese Islands.

Although variants of $\mathrm{ICD}_{\mathrm{S}}$, PEPA and PEPB were also encountered in this study, they were significantly less frequent than PHI variants. Among these variants, those of PEPB were more frequent. However, there are only a few preliminary reports of variation in the peptidase system in the Japanese. This study and the work of others suggest that none of the loci determining red cell peptidase in the Japanese are polymorphic. Thus, this PEPB variant may be widespread, though at a low frequency, throughout Japan.

\section{SUMMARY}

This paper presents the results of an electrophoretic survey of approximately 4000 individuals from Hiroshima and Nagasaki for four erythrocyte enzymes: isocitrate dehydrogenase, peptidase $\mathrm{A}$, peptidase $\mathrm{B}$, and phosphohexose isomerase. Also reported are the results for erythrocyte acid phosphatase for a subset of these individuals. The frequencies for the $A C P_{1}^{\mathbf{A}}$ and $A C P_{1}^{\mathbf{B}}$ alleles of the $\mathrm{ACP}_{1}$ locus are in agreement with previously reported results from Japanese populations. Rare variants of $\mathrm{ICD}_{\mathrm{S}}$, PEPA, PEPB and PHI occur with frequencies varying from $0 \cdot 25$ to $7 \cdot 2$ per 1000 determinations. The relatively high frequency of the PHI $4_{\mathrm{HIR}}$ variant and some unusual features involving the effect of reducing agent on the electrophoretic pattern behaviour of some of the rare PHI variants detected during this study are discussed.

\section{REFERENCES}

Brake, N. M., Омото, K., Kirk, R. L. \& Gajdusek, D. C. (1972). Variation in red cell enzymo groups among populations of the western Caroline Islands, Micronesia. Am. J. Hum. Genet. 25, 413.

Chen, S., Fossum, B. L. G. \& GibletT, E. R. (1972). Genetic variation of the soluble form of NADP. dependent isocitrate dehydrogenase in man. Am. J. Hum. Genet. 24, 325.

DetTer, J. C., Ways, P. O., Giblett, E. R., Baughan, M. A., Hopkinson, D. A., Povey, S. \& Harris, H. (1968). Inherited variations of human phosphohexose isomerase. Ann. Hum. Genet., Lond. $31,329$.

Ferrell, R. E., Ueda, N., Satoh, C., Tanis, R. J., Neel, J. V., Hamilton, H. B. \& Baba, K. The frequency in Japanese of genetic variants of 22 proteins. I. Albumin, ceruloplasmin, haptoglobin and transferrin. Ann. Hum. Genet., Lond. 40, 407.

Fildes, R. A. \& Harris, H. (1966). Genetically determined variation of adenylate kinase in man. Nature, Lond. 209, 261.

Harada, S., Akish, S., Kudo, T. \& Omoto, K. (1971). Distribution of phenotypes and gene frequencies of six red cell enzymes in the district of Tohoku, northern part of Japan. J. Anthrop. Soc. Nippon $79,356$.

Hopkinson, D. A. (1970). The investigation of reactive sulphydryls in enzymes and their variants by starchgel electrophoresis: Studies on the human phosphohexose isomerase variant PHI 5-1. Ann. Hum. Genet., Lond. 34, 79.

Hopkinson, D. A., Spencer, N. \& Harris, H. (1964). Genetical studies on human red cell acid phosphatase. Am. J. Hum. Genet. 16, 141.

Isнтмото, G. (1975). Red cell enzymes. Chap. 3 in Human Adaptability. Vol. 2. Anthropological and Genetic Studies on the Japanese (ed. S. Watanabe, S. Kondo and E. Matsunaga), p. 109. Tokyo: University of Tokyo Press.

Ishimoto, G. \& Kuwata, M. (1974). Electrophoretic variants of red cell phosphohexose isomerase in Japan. Jap. J. Hum. Genet. 18, 356.

Ishmoto, G. \& Kuwata, M. (1973a). Studies on the polymorphic types of ten blood proteins in Kyushu district, southern part of Japan. Jap. J. Legal Med. 27, 346.

Ismimoto, G. \& Kuwata, M. (1973b). Inherited variation of some red cell enzymes in Japan (2nd report). Jap. J. Legal Med. 27, 488.

Ishimoto, G. \& Kuwata, M. (1973c). A survey of inherited blood protein variations in Amami Oshima Island, southernmost part of Japan. J. Anthrop. Soc. Nippon 81, 153. 
Ishimoto, G., Kuwata, M. \& Kubota, S. (1973). Red cell enzyme polymorphisms in Japanese populations: A study on distribution of the phenotypes and forensic use in paternity cases. Jap. J. Legal Med. $27,134$.

LEwis, W. H. P. (1973). Common polymorphism of peptidase A. Electrophoretic variants associated with quantitation variation of red cell levels. Ann. Hum. Genet., Lond. 36, 267.

Lewis, W. H. P. \& Harris, H. (1967). Human red cell peptidase. Nature, Lond. $215,351$.

Neel, J. V., Ferrelt, R. E. \& Conard, R. (1976). The frequency of 'rare' protein variants in Marshall Islanders and other Micronesians. Am. J. Hum. Genet. 28, 262.

Омото, K. \& Blake, N. N. (1972). Distribution of genetic variants of erythrocyte phosphoglycerate kinase (PGK) and phosphohexose isomerase (PHI) among some population groups in south-east Asia and Oceania. Ann. Hum. Genet., Lond. 36, 61.

Oмото, K. \& Harada, S. (1972). The distribution of polymorphic traits in the Hidaka Ainu. II. Red cell enzymes and serum protein groups. J. Fac. Sci. Univ. Tokyo (sect. vI) 4 (2), 171.

Shaw, C. R. \& Prasad, R. (1970). Starch gel electrophoresis of enzymes - A compilation of recipes. Biachem. Genet. 4, 297.

ShINodA, T. (1970). Inherited variations in red cell phosphoglucose isomerase among Japanese. Jap. J. Hum. Genet. 15, 159.

Shinoda, T. \& Matsunaga, E. (1970). Frequencies of polymorphic types of several red cell enzymes in a Japanese population. Jap. J. Hum. Genet. 15, 133.

Shinoda, T., Matsunaga, E. \& Koshinaga, J. (1974). Isozyme variation in man. Jap. J. Hum. Genet. $19,57$.

Ueda, N., Sator, C., Tanis, R. J., Ferrell, R. E., Kishimoto, S., Neel, J. V., Hamilon, H. B. \& Baba, K. (1977). The frequency in Japanese of genetic variants of 22 proteins. II. Carbonic anhydrase I and II, lactate dehydrogenase, malate dehydrogenase, nucleoside phosphorylase, triose phosphate isomerase, haemoglobin A and haemoglobin $\mathrm{A}_{2}$. Ann. Hum. Genet., Lond. 41, 43. 